OPEN ACCESS

Edited by:

Erica L. Scheller,

Washington University School of

Medicine, USA

Reviewed by:

Gretchen Meyer,

Washington University, USA

Amanda L. Lorbergs,

Harvard Medical School, USA

${ }^{*}$ Correspondence:

Mark W. Hamrick

mhamrick@augusta.edu

Specialty section: This article was submitted

to Bone Research,

a section of the journal

Frontiers in Endocrinology

Received: 02 May 2016

Accepted: 07 June 2016

Published: 20 June 2016

Citation:

Hamrick MW, McGee-Lawrence ME and Frechette DM (2016) Fatty

Infiltration of Skeletal Muscle:

Mechanisms and Comparisons with

Bone Marrow Adiposity.

Front. Endocrinol. 7:69.

doi: 10.3389/fendo.2016.00069

\section{Fatty Infiltration of Skeletal Muscle: Mechanisms and Comparisons with Bone Marrow Adiposity}

\author{
Mark W. Hamrick ${ }^{1 *}$, Meghan E. McGee-Lawrence ${ }^{1}$ and Danielle M. Frechette ${ }^{2}$ \\ 'Department of Cellular Biology and Anatomy, Medical College of Georgia, Augusta, GA, USA, ${ }^{2}$ Department of Biomedical \\ Engineering, Stony Brook University, Stony Brook, NY, USA
}

Skeletal muscle and bone share common embryological origins from mesodermal cell populations and also display common growth trajectories early in life. Moreover, muscle and bone are both mechanoresponsive tissues, and the mass and strength of both tissues decline with age. The decline in muscle and bone strength that occurs with aging is accompanied in both cases by an accumulation of adipose tissue. In bone, adipocyte (AC) accumulation occurs in the marrow cavities of long bones and is known to increase with estrogen deficiency, mechanical unloading, and exposure to glucocorticoids. The factors leading to accumulation of intra- and intermuscular fat (myosteatosis) are less well understood, but recent evidence indicates that increases in intramuscular fat are associated with disuse, altered leptin signaling, sex steroid deficiency, and glucocorticoid treatment, factors that are also implicated in bone marrow adipogenesis. Importantly, accumulation of ACs in skeletal muscle and accumulation of intramyocellular lipid are linked to loss of muscle strength, reduced insulin sensitivity, and increased mortality among the elderly. Resistance exercise and whole body vibration can prevent fatty infiltration in skeletal muscle and also improve muscle strength. Therapeutic strategies to prevent myosteatosis may improve muscle function and reduce fall risk in the elderly, potentially impacting the incidence of bone fracture.

Keywords: bone marrow adipogenesis, myosteatosis, intramyocellular lipid, exercise

\section{INTRODUCTION}

Osteoporosis affects $\sim 10$ million people in the U.S. and results in over 1.5 million bone fractures per year. Hip fractures are a major cause of morbidity and mortality among the elderly: $\sim 40 \%$ of those suffering a hip fracture will end up in a nursing home and $20 \%$ will never walk again. In addition, the 1-year mortality of hip fractures at age 70 is $\sim 30 \%$. Muscle weakness and postural instability are major contributors to the incidence of falls among the elderly, and falling is the primary etiological factor in more than $75 \%$ of hip fractures (1). Loss of muscle and bone mass with age is therefore a significant public health problem, as the morbidity that accompanies fractures in the elderly is costly both in terms of financial burden and quality of life. The mechanisms underlying loss of muscle and bone strength with age are complex and multifactorial in nature, but evidence suggests that common factors regulate the integrated growth, development, and degeneration of these two tissues. For example, skeletal muscle and bone share common embryological origins from mesodermal cell populations and also display common growth trajectories early in life. Moreover, muscle and bone 
are both mechanoresponsive tissues, and the mass and strength of both tissues decline with age. Importantly, the decline in muscle and bone strength that occurs with aging is accompanied in both cases by an accumulation of adipose tissue. This accumulation of fat in non-adipose depots, such as bone, liver, and muscle, is now recognized as a common feature of aging (2). The processes driving the accumulation of bone marrow adipocytes (ACs) are becoming more well understood $(3,4)$; however, the factors leading to the accumulation of fat in skeletal muscle (myosteatosis) with age are not yet as well defined. Evidence, to date, does suggest that many of the factors that have been observed to stimulate bone marrow adipogenesis, such as estrogen deficiency, glucocorticoid treatment, and disuse atrophy, also induce myosteatosis. In this study, we review these findings to highlight potential therapeutic strategies for the prevention of age-related myosteatosis as an approach for reducing fall risk and hence the likelihood of bone fracture.

\section{FACTORS CONTRIBUTING TO BONE MARROW ADIPOGENESIS}

Bone cell populations are heterogeneous and include cells of both hematopoietic (e.g., megakaryocytes and osteoclasts) and mesenchymal (e.g., osteoblasts and AC) origin. Aging is accompanied by an accumulation of $\mathrm{AC}$ as well as increase in ACs size within the bone marrow cavity (5). Adipose tissue represents $\sim 20 \%$ of bone marrow tissue before the third decade in life but increases to nearly $50 \%$ by the ninth decade (6). This accumulation of bone marrow fat shows a strong association with bone loss, reduced bone formation, and fracture risk (6-9). Mesenchymal progenitors (MSCs) within bone marrow can be directed toward the AC or osteoblast lineage, and conditions that favor adipogenesis such as estrogen depletion (10), disuse (11), anorexia/calorie restriction $(12,13)$, and exposure to microgravity (14) are also associated with reduced osteoblast differentiation.

In addition, there are a number of pharmaceutical treatments that can mediate bone marrow adipogenesis. For example, glucocorticoids and PPAR gamma agonists will stimulate adipogenesis in mesenchymal progenitors $(15,16)$, whereas lipid-lowering statins can inhibit adipogenic differentiation (17). Importantly, the microenvironment of the MSCs plays a key role in modulating this reciprocal switch between adipogenic or osteogenic differentiation, particularly with aging, as young MSCs transplanted into old animals or young MSCs exposed to serum of old donors will tend to differentiate down the adipogenic pathway rather than become osteogenic $(18,19)$. Finally, epigenetic programing also appears to play an important role in modulating bone marrow adipogenesis. For example, conditional deletion of Hdac3 in preosteoblasts increases marrow AC number and lipid storage in preosteoblasts (20). It is worth noting that marrow ACs are themselves not homogenous in their gene expression and secretory profile. For example, some marrow ACs are similar to "white" fat in being rich in saturated fatty acids, whereas other marrow ACs are more "beige-like" fat in having greater thermogenic potential (4).

\section{FATTY INFILTRATION IN SKELETAL MUSCLE: CELLULAR AND MOLECULAR MECHANISMS}

Aging in humans is accompanied by a loss of subcutaneous fat but an accumulation of AC and lipids in non-adipose depots, such as bone marrow, liver, and skeletal muscle (2). Fatty infiltration of skeletal muscle (myosteatosis) has, in particular, been recognized as an important component of aging and frailty (21-26). Lipid accumulation in muscles of the lower limb is also associated with increased fracture risk in the elderly (27). The cellular origins of fatty accumulation in muscle arise through several different pathways (Figure 1). One direct route is via the accumulation of lipid within myofibers themselves, known as intramuscular fat or intramyocellular (IMC) lipid (28-30). Accumulation of IMC lipid is now known to be associated with insulin insensitivity, inflammation, and functional deficits in skeletal muscle. Accumulation of the sphingolipid ceramide appears to have a particularly

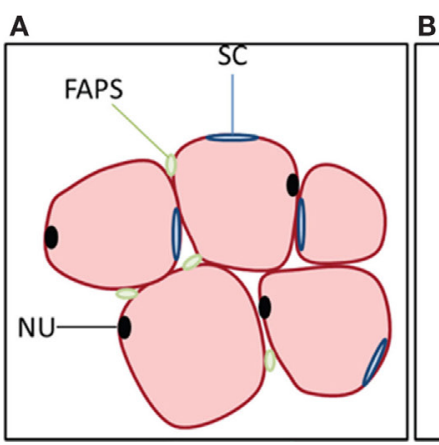

B

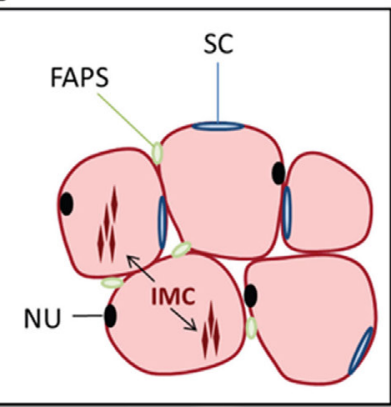

C

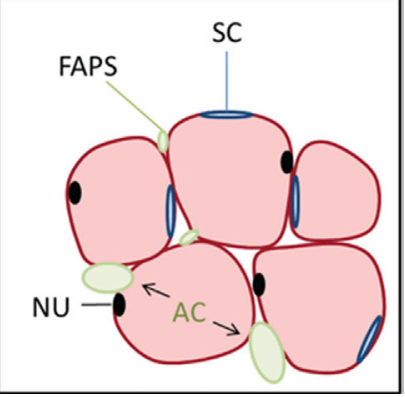

FIGURE 1 | Cell populations in muscle and their relationship to lipid accumulation. (A) Myofibers (pink) are multinucleated (NU, nucleus, black) and surrounded by satellite cells (SCs, blue) as well as multipotential cells of mesenchymal origin referred to as fibro-adipogenic progenitors (FAPs, green). FAPs are distinct from satellite cells and lack Pax7 expression but are Sca-1 and PDGFR $\alpha$ positive. Not shown are pericytes surrounding blood vessels within muscle. (B) Intramyocellular (IMC) lipid can accumulate within myofibers, which is one pathway for lipid deposition within skeletal muscle. (C) FAPs can also differentiate to adipocytes (ACs), contributing to the accumulation of intermuscular fat, often following muscle injury. 
detrimental effect on skeletal muscle function (30). Recent data also suggest that the lipid metabolites diacylglycerols (DAG) are responsible for mediating insulin resistance in skeletal muscle through disrupting the insulin signaling pathway (31).

Another pathway for myosteatosis is an accumulation of AC within skeletal muscle, known as intermuscular fat. There are several stem cell populations in skeletal muscle, the most well defined being muscle satellite cells (SCs), which lie below the basil lamina of muscle fibers and contribute to myogenesis during the process of muscle regeneration. A second, more recently described, population of cells is termed fibro/adipogenic progenitors (FAPs) or mesenchymal interstitial cells [Figure 1; Ref. (32-35)]. These cells are distinct from SCs and lack Pax7 expression but are Sca-1 and PDGFR $\alpha$ positive. SCs are generally resistant to adipogenic differentiation, whereas FAPs readily differentiate into ACs under various conditions such as muscle injury or glucocorticoid treatment $(34,36)$. Endogenous glucocorticoid levels increase with age (37), which may contribute not only to accumulation of bone marrow ACs but also to the deposition of intermuscular fat with age. Multipotent mesenchymal stem cells and other progenitors may also contribute toward skeletal muscle adipogenesis. For example, $\mathrm{PW}^{+}$interstitial cells (PICs) have shown adipogenic potential in vitro (38); however, the extent to which this population overlaps with FAPs is unclear. Additionally, type-1 pericytes expressing PDGFR $\alpha$ have been shown to commit to the adipogenic lineage in vivo in the presence of glycerol (39).

Just as glucocorticoids can stimulate adipogenesis in both bone and muscle, other signaling pathways appear to be shared that regulate adipogenesis in muscle and bone (Figure 2). Wnt10b is well recognized to inhibit adipogenesis and stimulate bone formation in bone tissue (40). Wnt10b also suppresses the accumulation of IMC lipid in myofibers, increases insulin sensitivity, and inhibits adipogenic differentiation of aged, muscle-derived stem cells $(41,42)$. Similarly, inhibition of histone deacetylases (HDAC) can inhibit the adipogenic differentiation of MSCs in vitro and enhance their differentiation to osteoblasts (43), and HDAC inhibitors also inhibit the adipogenic differentiation of FAPs during the process of muscle regeneration (44). Altered leptin signaling, either due to absence of leptin or leptin receptors, is associated with increased bone marrow fat (45) as well as increased intra- and intermuscular fat (Figure 3). The leptin receptor is a key marker of bone marrow mesenchymal stem cells that mediate marrow adipogenesis (46), and the leptin receptor is also expressed in skeletal muscle (47). Whether or not the accumulation of inter- and intramuscular fat is directly mediated by the leptin receptor is, however, not well understood. Leptin deficiency associated with calorie restriction results in increased marrow adiposity (12), as does anorexia nervosa (48), but calorie restriction decreases lipid stores and lipid droplet size in skeletal muscle (49).

Unloading through either prolonged bedrest or spaceflight increases bone marrow adipogenesis $(11,14)$, and prolonged bedrest also decreases muscle strength and increases IMC lipid in skeletal muscle (50), which can ultimately lead to postural instability (51). Finally, estrogen deficiency is implicated in bone loss and marrow AC accumulation in women. Estrogen deficiency increases lipid content in skeletal muscle, the expression of adipogenic genes, and decreases relative satellite cell proportions in ovariectomized rodents $(52,53)$. Androgen deprivation therapy also increases fatty infiltration of skeletal muscle in men with prostate cancer, although CT imaging does not enable a distinction between IMC or intermuscular lipid accumulation and so

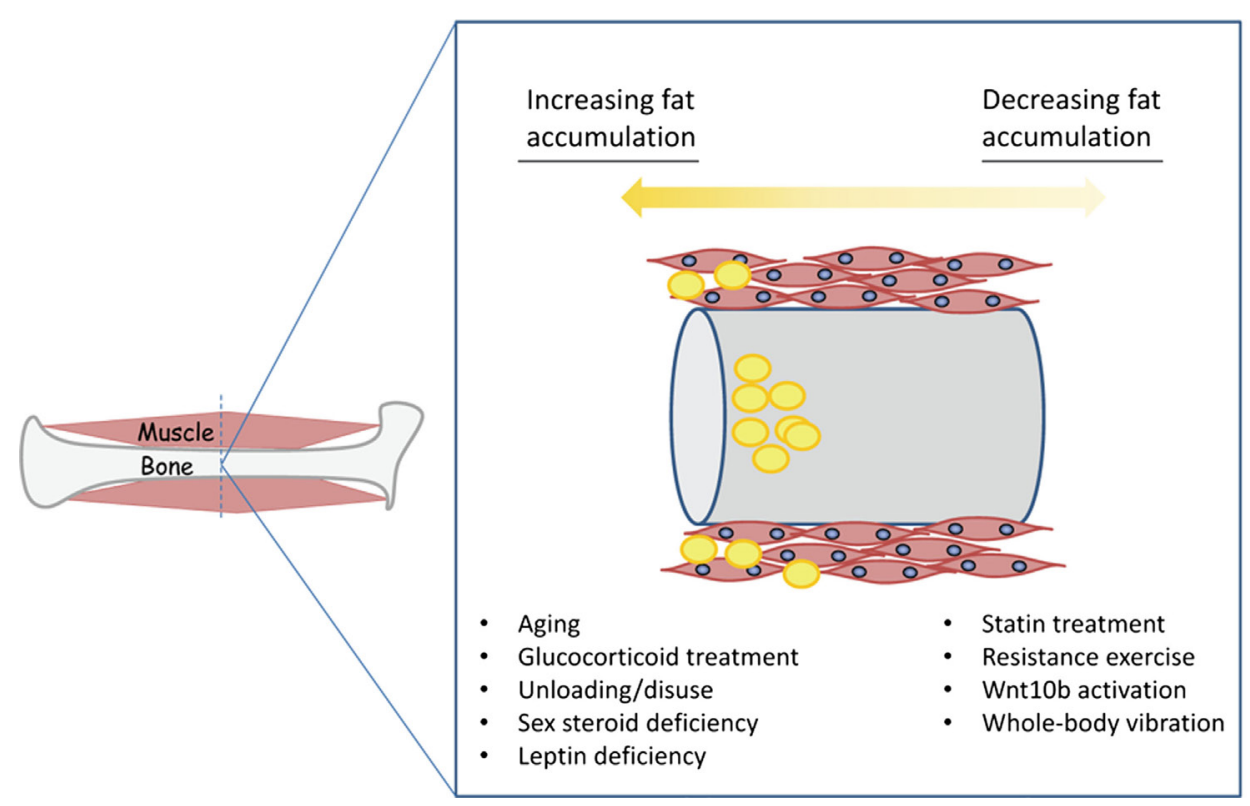

FIGURE 2 | Conditions favoring the accumulation of fat (yellow) in muscle and bone versus those conditions that can either prevent or possibly reverse fatty deposition in muscle and bone. 


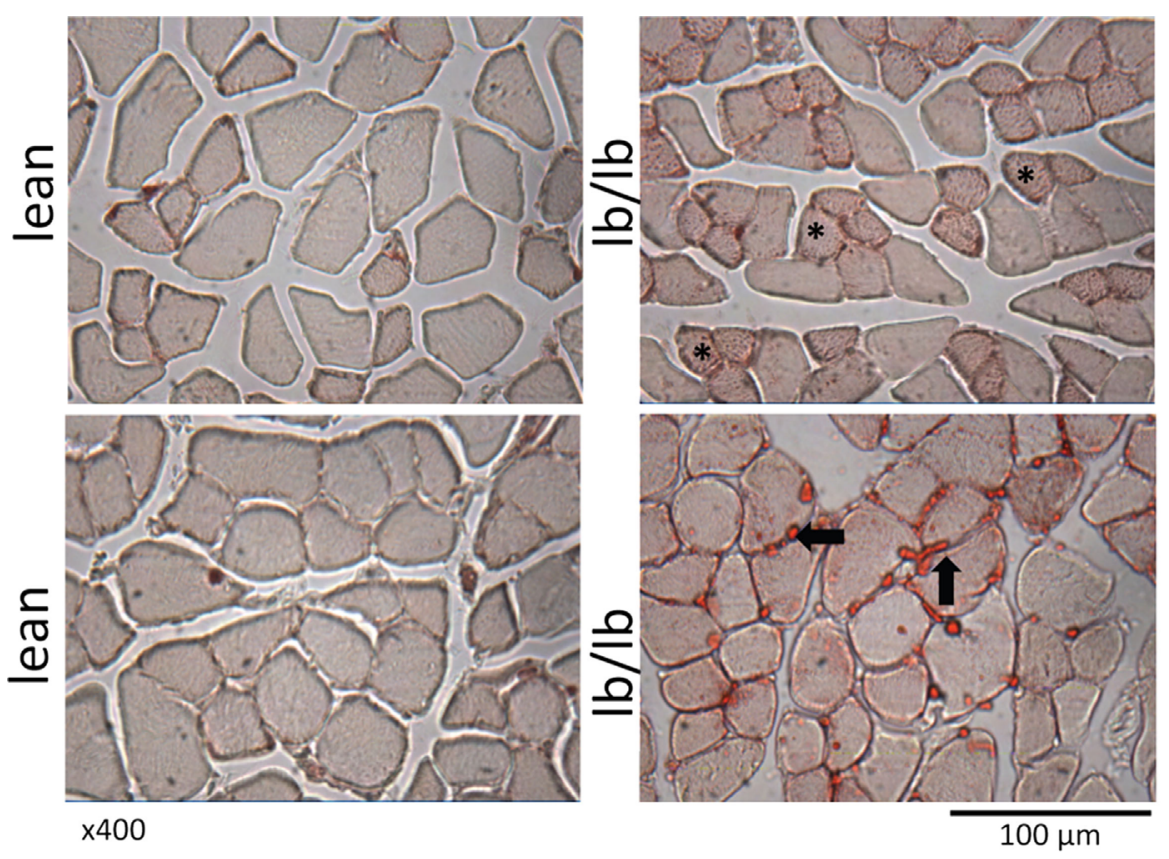

FIGURE 3 | Cross sections of muscle fibers from normal, lean mice (left), or mice that lack leptin receptors (lb/lb, right) stained for oil red 0 . The asterisks indicate the accumulation of intramyocellular lipid, and the arrows indicate intermuscular fat. Note also the relatively small diameter of fibers that are positive for intramyocellular lipid. POUND mice (lb/lb) lack both short and long forms of the leptin receptor and are obese and hyperphagic (47).

the actual site of lipid deposition is not clear in this case (54). Together, these findings indicate that many of the conditions that induce marrow adipogenesis and bone loss in men and women such as disuse, sex steroid deficiency, altered leptin signaling, and glucocorticoid treatment also stimulate the accumulation of ACs and IMC lipid in skeletal muscle (Figure 2).

\section{FUNCTIONAL CONSEQUENCES OF FATTY INFILTRATION IN MUSCLE}

Protein synthesis enhances muscle hypertrophy and the maintenance of muscle strength, whereas impaired protein synthesis contributes to muscle atrophy. Insulin is an anabolic factor for skeletal muscle, and accumulation of muscle ACs and IMC lipid decreases insulin sensitivity, impairing the capacity for normal protein synthesis in skeletal muscle (30). Thus, decreased insulin sensitivity with fatty infiltration in skeletal muscle is one pathway by which fatty infiltration can directly affect muscle mass and muscle strength. The accumulation of IMC lipid with aging or with disuse is not homogenous across different muscles or different fiber types. This may be analogous to the unequal distribution of ACs throughout bone marrow in the appendicular skeleton, where fatty infiltration begins at more distal skeletal locations (55). For example, within the posterior compartment of the leg, the gastrocnemius accumulates more lipid with age than other calf muscles (21). Type I fibers, also referred to as "slow-twitch oxidative fibers," tend to accumulate more IMC lipid with age in human subjects than fast-twitch oxidative fibers $(23,25)$, and fast-twitch fibers typically show greater atrophy with age than type I fibers $(23,56)$. It is possible that lipid accumulation alone may even support a transition of type II fibers to more of a type I phenotype (57). These changes ultimately lead to muscles with impaired contractile capacity of both type I and type II fibers, which together lead the dramatic decrease in muscle power (product of force and speed) observed with age (58).

Aging and disuse can induce the accumulation of IMC lipid, but muscle injury is associated with a marked accumulation of intermuscular fat (ACs), likely derived from the FAPs referenced above. This phenomenon has been most well described in patients with Duchene muscular dystrophy (DMD), where the prolonged cycle of muscle injury and regeneration that accompanies dystrophin deficiency ultimately results in an accumulation of ACs and fibrous tissue in areas where muscle fibers are lost $(59,60)$. The loss of muscle fibers and replacement with fatty and fibrous tissues leads to muscle weakness. The extent to which muscle injury with aging, which might occur with frequent eccentric muscle contractions, contributes to accumulation of intermuscular fat is not well documented. Fatty infiltration of skeletal muscle is also common following rotator cuff muscle injury and is a major factor that limits functional recovery (61). Attenuation of fatty infiltration following rotator cuff injury with statin treatment can have a protective effect on muscle atrophy in rats (62); however, a number of studies in human subjects indicate that fatty infiltration and muscle atrophy after rotator cuff repair is very difficult to reverse $(63,64)$. Hyperlipidemia and type 2 diabetes are independent risk factors for rotator cuff injury (65). It is certainly 
possible that these risk factors may not only increase the risk of rotator cuff injury but also may contribute to an attenuated repair response following treatment by exacerbating fatty infiltration of the injured rotator cuff muscles.

\section{DISCUSSION: TARGETING ADIPOGENESIS AND LIPID ACCUMULATION IN MUSCLE TO PREVENT FRACTURE}

One of the most effective countermeasures against fatty infiltration of muscle with aging is physical activity and regular exercise. Previous work indicates that 6 months of regular aerobic exercise combined with weight loss reduced low-density muscle (lipid measurement) and improved glucose tolerance in men aged $60+$ years compared with those who just exercised alone (66). Resistance training 3 days/week in adults' age 55+ years decreased thigh intramuscular adipose tissue (67), and 1 year of brisk walking prevented fatty infiltration of muscle in older subjects (68). Importantly, resumption of physical activity following periods of sedentary activity could reverse the fatty infiltration that occurred in older adults following cessation of resistance training (69). Fracture risk in women declines with higher levels of weekly physical activity (70), and hip fracture in men is more common in those individuals with low physical activity compared with men with higher levels of physical activity (71). Resistance exercise increases leg strength and power in both older (aged 70 years) men and women (72), and this increase is associated with increased muscle fiber size (73). While the effects of exercise on bone and perhaps bone marrow ACs are more modest (74), resistance training may have a positive effect on reducing fracture risk by reducing intramuscular fat and increasing muscle strength and power.

Alternative forms of mechanical signals that are safe and can help prevent accumulation of muscular or bone marrow fat may

\section{REFERENCES}

1. Järvinen TL, Sievänen H, Khan KM, Heinonen A, Kannus P. Shifting the focus in fracture prevention from osteoporosis to falls. BMJ (2008) 336:124-6. doi:10.1136/bmj.39428.470752.AD

2. Kirkland JL, Tchkonia T, Pirtskhalava T, Han J, Karagiannides I. Adipogenesis and aging: does aging make fat go MAD? Exp Gerontol (2002) 37:757-67. doi:10.1016/S0531-5565(02)00014-1

3. Rosen CJ, Bouxsein ML. Mechanisms of disease: is osteoporosis the obesity of bone? Nat Clin Pract Rheumatol (2006) 2:35-43. doi:10.1038/ncprheum0070

4. Hardouin P, Marie PJ, Rosen CJ. New insights into bone marrow adipocytes: report from the first European meeting on bone marrow adiposity (BMA 2015). Bone (2015) S8756-3282(15):414-7. doi:10.1016/j.bone.2015.11.013

5. Meunier P, Aaron J, Edouard C, Vignon G. Osteoporosis and the replacement of cell populations of the marrow by adipose tissue. Clin Orthop Relat Res (1971) 80:147-54. doi:10.1097/00003086-197110000-00021

6. Schellinger D, Lin CS, Hatipoglu HG, Fertikh D. Potential value of vertebral proton MR spectroscopy in determining bone weakness. AJNR Am J Neuroradiol (2001) 22:1620-7.

7. Justesen J, Stenderup K, Ebbesen E, Mosekilde L, Steiniche T, Kasse M. Adipocyte tissue volume in bone marrow is increased with aging and in patients with osteoporosis. Biogerontol (2001) 2:165-71. doi:10.102 3/A:1011513223894 be desirable, particularly, for the elderly or injured who are unable to exercise or have increased risk of fracture. Low magnitude ( $<1 \mathrm{~g} ; g=$ earth's gravitational field), whole body vibration has been observed to reduce adipose tissue as well as the expression of adipogenic genes in muscle $(53,75)$ while also acting as an anabolic signal and increasing muscle fiber area (76). Similarly, vibration has reduced bone marrow adiposity in a model of postmenopausal osteoporosis (77) and reduced bone marrowderived mesenchymal stem cell commitment to the adipogenic lineage (78). Reduced indices of adipogenesis with the application of these mechanical signals as seen in both muscle and bone may occur through a similar mechanism - bias of mesenchymal stem cell or fate away from the fat differentiation pathway. These findings suggest that mechanical stimulation in a relatively low magnitude, high-frequency domain may have the potential to preserve muscle function with age by reducing the accumulation of lipids and ACs in skeletal muscle.

\section{AUTHOR CONTRIBUTIONS}

$\mathrm{MH}$ wrote the initial draft and prepared the manuscript illustrations. MM-L contributed additional narrative material on bone marrow adipogenesis and edited the manuscript. DF contributed narrative material on exercise and whole body vibration and on myosteatosis. DF also edited the manuscript.

\section{ACKNOWLEDGMENTS}

The authors are grateful to E. Scheller and W. Cawthorn for the opportunity to prepare this contribution. Funding to $\mathrm{MH}$ is provided by the National Institute on Aging (NIA AG036675) and funding to MM-L is provided by the American Diabetes Association (1-16-JDF-062). The authors thank Donna Kumiski in the Electron Microscopy and Histology Core Facility for her assistance with the staining shown in Figure 2.

8. Verma S, Rajaratnam JH, Denton J, Hoyland JA, Byers RJ. Adipocytic proportion of bone marrow is inversely related to bone formation in osteoporosis. J Clin Pathol (2002) 55:693-8. doi:10.1136/jcp.55.9.693

9. Patsch JM, Li X, Baum T, Yap SP, Karampinos DC, Schwartz AV, et al. Bone marrow fat composition as a novel imaging biomarker in postmenopausal women with prevalent fragility fractures. J Bone Miner Res (2013) 28(8):17218. doi:10.1002/jbmr.1950

10. Nuttall M, Gimble J. Is there a therapeutic opportunity to either prevent or treat osteopenic disorders by inhibiting marrow adipogenesis? Bone (2000) 27:177-84. doi:10.1016/S8756-3282(00)00317-3

11. Minaire P, Meunier P, Edouard C, Berbard J, Courpron J, Bourret J. Quantitative histological data on disuse osteoporosis. Calcif Tissue Res (1974) 13:371-82.

12. Devlin MJ, Cloutier AM, Thomas NA, Panus DA, Lotinun S, Pinz I, et al. Caloric restriction leads to high marrow adiposity and low bone mass in growing mice. J Bone Miner Res (2010) 25:2078-88. doi:10.1002/ jbmr.82

13. Cawthorn WP, Scheller EL, Learman BS, Parlee SD, Simon BR, Mori H, et al. Bone marrow adipose tissue is an endocrine organ that contributes to increased circulating adiponectin during caloric restriction. Cell Metab (2014) 20:368-75. doi:10.1016/j.cmet.2014.06.003

14. Wronski T, Morey-Holton E, Jee W. Skeletal alterations in rats during spaceflight. Adv Space Res (1981) 1:135-40. doi:10.1016/0273-1177(81) 90254-4 
15. Cui Q, Wang GJ, Balian G. Pluripotential marrow cells produce adipocytes when transplanted into steroid-treated mice. Connect Tissue Res (2000) 41:45-56. doi:10.3109/03008200009005641

16. Akune T, Ohba S, Kamekura S, Yamaguchi M, Chung UI, Kubota N, et al. PPAR gamma insufficiency enhances osteogenesis through osteoblast formation from bone marrow progenitors. J Clin Invest (2004) 113:846-55. doi:10.1172/JCI200419900

17. Li X, Cui Q, Kao C, Wang GJ, Balian G. Lovastatin inhibits adipogenic and stimulates osteogenic differentiation by suppressing PPARgamma2 and increasing Cbfa1/Runx2 expression in bone marrow mesenchymal cell cultures. Bone (2003) 33:652-9. doi:10.1016/S8756-3282(03)00239-4

18. Abdallah BM, Haack-Sørensen M, Fink T, Kassem M. Inhibition of osteoblast differentiation but not adipocyte differentiation of mesenchymal stem cells by sera obtained from aged females. Bone (2006) 39:181-8. doi:10.1016/j. bone.2005.12.082

19. Singh L, Brennan TA, Russell E, Kim JH, Chen Q, Brad Johnson F, et al. Aging alters bone-fat reciprocity by shifting in vivo mesenchymal precursor cell fate towards an adipogenic lineage. Bone (2016) 85:29-36. doi:10.1016/j. bone.2016.01.014

20. McGee-Lawrence ME, Carpio LR, Schulze RJ, Pierce JL, McNiven MA, Farr JN, et al. Hdac3 deficiency increases marrow adiposity and induces lipid storage and glucocorticoid metabolism in osteochondroprogenitor cells. J Bone Miner Res (2016) 31:116-28. doi:10.1002/jbmr.2602

21. Tuttle LJ, Sinacore DR, Mueller MJ. Intermuscular adipose tissue is muscle specific and associated with poor functional performance. J Aging Res (2012) 2012:172957. doi:10.1155/2012/172957

22. Delmonico MJ, Harris TB, Visser M, Park SW, Conroy MB, VelasquezMieyer P, et al. Longitudinal study of muscle strength, quality, and adipose tissue infiltration. Am J Clin Nutr (2009) 90:1579-85. doi:10.3945/ajcn.2009. 28047

23. Gueugneau M, Coudy-Gandilhon C, Théron L, Meunier B, Barboiron C, Combaret L, et al. Skeletal muscle lipid content and oxidative activity in relation to muscle fiber type in aging and metabolic syndrome. J Gerontol A Biol Sci Med Sci (2015) 70:566-76. doi:10.1093/gerona/glu086

24. Miljkovic I, Kuipers AL, Cauley JA, Prasad T, Lee CG, Ensrud KE, et al. Greater skeletal muscle fat infiltration is associated with higher all-cause and cardiovascular mortality in older men. J Gerontol A Biol Sci Med Sci (2015) 70:1133-40. doi:10.1093/gerona/glv027

25. Choi SJ, Files DC, Zhang T, Wang ZM, Messi ML, Gregory H, et al. Intramyocellular lipid and impaired myofiber contraction in normal weight and obese older adults. JGerontol A Biol Sci Med Sci (2016) 71:557-64. doi:10.1093/gerona/glv169

26. Reinders I, Murphy RA, Brouwer IA, Visser M, Launer L, Siggeirsdottir K, et al. Muscle quality and myosteatosis: novel associations with mortality risk: the age, gene/environment susceptibility (AGES)-Reykjavik study. Am J Epidemiol (2016) 183:53-60. doi:10.1093/aje/kwv153

27. Lang T, Cauley JA, Tylavsky F, Bauer D, Cummings S, Harris TB, et al. Computed tomographic measurements of thigh muscle cross-sectional area and attenuation coefficient predict hip fracture: the health, aging, and body composition study. J Bone Miner Res (2010) 25(3):513-9. doi:10.1359/ jbmr.090807

28. Komolka K, Albrecht E, Wimmers K, Michal JJ, Maak S. Molecular heterogeneities of adipose depots - potential effects on adipose-muscle cross-talk in humans, mice and farm animals. J Genomics (2014) 2:31-44. doi:10.7150/ jgen. 5260

29. Kindler JM, Lewis RD, Hamrick MW. Skeletal muscle and pediatric bone development. Curr Opin Endocrinol Diabetes Obes (2015) 22:467-74. doi:10.1097/MED.0000000000000201

30. Rivas DA, McDonald DJ, Rice NP, Haran PH, Dolnikowski GG, Fielding RA. Diminished anabolic signaling response to insulin induced by intramuscular lipid accumulation is associated with inflammation in aging but not obesity. Am J Physiol Regul Integr Comp Physiol (2016) 310:R561-9. doi:10.1152/ ajpregu.00198.2015

31. Shulman GI. Ectopic fat in insulin resistance, dyslipidemia, and cardiometabolic disease. N Engl J Med (2014) 371:1131-41. doi:10.1056/NEJMra1011035

32. Uezumi A, Fukada S, Yamamoto N, Takeda S, Tsuchida K. Mesenchymal progenitors distinct from satellite cells contribute to ectopic fat cell formation in skeletal muscle. Nat Cell Biol (2010) 12:143-52. doi:10.1038/ncb2014
33. Penton CM, Thomas-Ahner JM, Johnson EK, McAllister C, Montanaro F. Muscle side population cells from dystrophic or injured muscle adopt a fibro-adipogenic fate. PLoS One (2013) 8:e54553. doi:10.1371/journal. pone. 0054553

34. Dong Y, Silva KA, Dong Y, Zhang L. Glucocorticoids increase adipocytes in muscle by affecting IL-4 regulated FAP activity. FASEB J (2014) 28:4123-32. doi:10.1096/fj.14-254011

35. Farup J, Madaro L, Puri PL, Mikkelsen UR. Interactions between muscle stem cells, mesenchymal-derived cells and immune cells in muscle homeostasis, regeneration and disease. Cell Death Dis (2015) 6:e1830. doi:10.1038/ cddis. 2015.198

36. Agley CC, Rowlerson AM, Velloso CP, Lazarus NR, Harridge SD. Human skeletal muscle fibroblasts, but not myogenic cells, readily undergo adipogenic differentiation. J Cell Sci (2013) 126(Pt 24):5610-25. doi:10.1242/ jcs. 132563

37. Weinstein RS, Wan C, Liu Q, Wang Y, Almeida M, O’Brien CA, et al. Endogenous glucocorticoids decrease skeletal angiogenesis, vascularity, hydration, and strength in aged mice. Aging Cell (2010) 9:147-61. doi:10.1111/j.1474-9726.2009.00545.x

38. Pannerec A, Formicola L, Besson V, Marazzi G, Sassoon DA. Defining skeletal muscle resident progenitors and their cell fate potentials. Development (2013) 140:2879-91. doi:10.1242/dev.089326

39. Birbrair A, Zhang T, Wang ZM, Messi ML, Enikolopov GN, Mintz A, et al. Role of pericytes in skeletal muscle regeneration and fat accumulation. Stem Cells Dev (2013) 22:2298-314. doi:10.1089/scd.2012.0647

40. Bennett CN, Longo KA, Wright WS, Suva LJ, Lane TF, Hankenson KD, et al. Regulation of osteoblastogenesis and bone mass by Wnt10b. Proc Natl Acad Sci U S A (2005) 102:3324-9. doi:10.1073/pnas.0408742102

41. Taylor-Jones JM, McGehee RE, Rando TA, Lecka-Czernik B, Lipschitz DA, Peterson CA. Activation of an adipogenic program in adult myoblasts with age. Mech Ageing Dev (2002) 123:649-61. doi:10.1016/S0047-6374(01)00411-0

42. Abiola M, Favier M, Christodoulou-Vafeiadou E, Pichard AL, Martelly I, Guillet-Deniau I. Activation of Wnt/beta-catenin signaling increases insulin sensitivity through a reciprocal regulation of Wnt $10 \mathrm{~b}$ and SREBP-1c in skeletal muscle cells. PLoS One (2009) 4(12):e8509. doi:10.1371/journal.pone.0008509

43. Xu Y, Hammerick KE, James AW, Carre AL, Leucht P, Giaccia AJ, et al. Inhibition of histone deacetylase activity in reduced oxygen environment enhances the osteogenesis of mouse adipose-derived stromal cells. Tissue Eng Part A (2009) 15:3697-707. doi:10.1089/ten.TEA.2009.0213

44. Saccone V, Consalvi S, Giordani L, Mozzetta C, Barozzi I, Sandoná M, et al. HDAC-regulated myomiRs control BAF60 variant exchange and direct the functional phenotype of fibro-adipogenic progenitors in dystrophic muscles. Genes Dev (2014) 28:841-57. doi:10.1101/gad.234468.113

45. Hamrick MW, Della-Fera MA, Choi YH, Pennington C, Hartzell D, Baile CA. Leptin treatment induces loss of bone marrow adipocytes and increases bone formation in leptin-deficient ob/ob mice. JBone Miner Res (2005) 20:994-1001. doi:10.1359/JBMR.050103

46. Yue R, Zhou BO, Shimada IS, Zhao Z, Morrison SJ. Leptin receptor promotes adipogenesis and reduces osteogenesis by regulating mesenchymal stromal cells in adult bone marrow. Cell Stem Cell (2016) 18(6):782-96. doi:10.1016/j. stem.2016.02.015

47. Arounleut P, Bowser M, Upadhyay S, Shi X-M, Fulzele S, Johnson M, et al. Absence of functional leptin receptor isoforms in the POUND (Lepr $\mathrm{db} / \mathrm{lb}$ ) mouse is associated with muscle atrophy and altered myoblast proliferation and differentiation. PLoS One (2013) 8:e72330. doi:10.1371/ annotation/3a7d6e24-137c-4603-93ca-879bec7fab80

48. Devlin MJ. Why does starvation make bones fat? Am J Hum Biol (2011) 23(5):577-85. doi:10.1002/ajhb.21202

49. Shaw CS, Clark J, Wagenmakers AJ. The effect of exercise and nutrition on intramuscular fat metabolism and insulin sensitivity. Annu Rev Nutr (2010) 30:13-34. doi:10.1146/annurev.nutr.012809.104817

50. Cree M, Paddon-Jones D, Newcomer B, Ronsen O, Aarsland A, Wolfe R, et al. Twenty-eight-day bed rest with hypercortisolemia induces peripheral insulin resistance and increases intramuscular triglycerides. Metabolism (2010) 59:703-10. doi:10.1016/j.metabol.2009.09.014

51. Muir J, Judex S, Qin YX, Rubin C. Postural instability caused by extended bed rest is alleviated by brief daily exposure to low magnitude mechanical signals. Gait Posture (2011) 33:429-35. doi:10.1016/j.gaitpost.2010.12.019 
52. Leite RD, Prestes J, Bernardes CF, Shiguemoto GE, Pereira GB, Duarte JO, et al. Effects of ovariectomy and resistance training on lipid content in skeletal muscle, liver, and heart; fat depots; and lipid profile. Appl Physiol Nutr Metab (2009) 34:1079-86. doi:10.1139/H09-116

53. Frechette DM, Krishnamoorthy D, Adler BJ, Chan ME, Rubin CT. Diminished satellite cells and elevated adipogenic gene expression in muscle as caused by ovariectomy are averted by low-magnitude mechanical signals. J Appl Physiol (2015) 119:27-36. doi:10.1152/japplphysiol.01020.2014

54. Chang D, Joseph DJ, Ebert MA, Galvão DA, Taaffe DR, Denham JW, et al. Effect of androgen deprivation therapy on muscle attenuation in men with prostate cancer. J Med Imaging Radiat Oncol (2014) 58:223-8. doi:10.1111/1754-9485.12124

55. Scheller EL, Troiano N, Vanhoutan JN, Bouxsein MA, Fretz JA, Xi Y, et al. Use of osmium tetroxide staining with microcomputerized tomography to visualize and quantify bone marrow adipose tissue in vivo. Methods Enzymol (2014) 537:123-39. doi:10.1016/B978-0-12-411619-1.00007-0

56. Novotny SA, Warren GL, Hamrick MW. Aging and the muscle-bone relationship. Physiology (Bethesda) (2015) 30(1):8-16. doi:10.1152/physiol.00033. 2014

57. Mastrocola R, Collino M, Nigro D, Chiazza F, D’Antona G, Aragno M, et al. Accumulation of advanced glycation end-products and activation of the SCAP/SREBP lipogenetic pathway occur in diet-induced obese mouse skeletal muscle. PLoS One (2015) 10(3):e0119587. doi:10.1371/journal. pone.0119587

58. Reid KF, Fielding RA. Skeletal muscle power: a critical determinant of physical functioning in older adults. Exerc Sport Sci Rev (2012) 40:4-12. doi:10.1097/ JES.0b013e31823b5f13

59. Yamanouchi K, Yada E, Ishiguro N, Hosoyama T, Nishihara M. Increased adipogenicity of cells from regenerating skeletal muscle. Exp Cell Res (2006) 312:2701-11. doi:10.1016/j.yexcr.2006.04.014

60. Hosoyama T, Ishiguro N, Yamanouchi K, Nishihara M. Degenerative muscle fiber accelerates adipogenesis of intramuscular cells via RhoA signaling pathway. Differentiation (2009) 77:350-9. doi:10.1016/j.diff.2008.11.001

61. Gumucio JP, Korn MA, Saripalli AL, Flood MD, Phan AC, Roche SM, et al. Aging-associated exacerbation in fatty degeneration and infiltration after rotator cuff tear. J Shoulder Elbow Surg (2014) 23:99-108. doi:10.1016/j. jse.2013.04.011

62. Davis ME, Korn MA, Gumucio JP, Harning JA, Saripalli AL, Bedi A, et al. Simvastatin reduces fibrosis and protects against muscle weakness after massive rotator cuff tear. J Shoulder Elbow Surg (2015) 24:280-7. doi:10.1016/j. jse.2014.06.048

63. Gerber C, Schneeberger AG, Hoppeler H, Meyer DC. Correlation of atrophy and fatty infiltration on strength and integrity of rotator cuff repairs: a study in thirteen patients. J Shoulder Elbow Surg (2007) 16(6):691-6. doi:10.1016/j. jse.2007.02.122

64. Gladstone JN, Bishop JY, Lo IK, Flatow EL. Fatty infiltration and atrophy of the rotator cuff do not improve after rotator cuff repair and correlate with poor functional outcome. Am J Sports Med (2007) 35(5):719-28. doi:10.1177/0363546506297539

65. Lin TT, Lin CH, Chang CL, Chi CH, Chang ST, Sheu WH. The effect of diabetes, hyperlipidemia, and statins on the development of rotator cuff disease: a nationwide, 11-year, longitudinal, population-based follow-up study. Am J Sports Med (2015) 43:2126-32. doi:10.1177/0363546515588173

66. Prior SJ, Joseph LJ, Brandauer J, Katzel LI, Hagberg JM, Ryan AS. Reduction in midthigh low-density muscle with aerobic exercise training and weight loss impacts glucose tolerance in older men. J Clin Endocrinol Metab (2007) 92:880-6. doi:10.1210/jc.2006-2113

67. Marcus RL, Addison O, Kidde JP, Dibble LE, Lastayo PC. Skeletal muscle fat infiltration: impact of age, inactivity, and exercise. J Nutr Health Aging (2010) 14:362-6. doi:10.1007/s12603-010-0081-2

68. Goodpaster BH, Chomentowski P, Ward BK, Rossi A, Glynn NW, Delmonico MJ, et al. Effects of physical activity on strength and skeletal muscle fat infiltration in older adults: a randomized controlled trial. J Appl Physiol (2008) 105:1498-503. doi:10.1152/japplphysiol.90425.2008

69. Taaffe DR, Henwood TR, Nalls MA, Walker DG, Lang TF, Harris TB. Alterations in muscle attenuation following detraining and retraining in resistance-trained older adults. Gerontology (2009) 55:217-23. doi:10.1159/000182084

70. Feskanich D, Willett W, Colditz G. Walking and leisure-time activity and risk of hip fracture in postmenopausal women. JAMA (2002) 288:2300-6. doi:10.1001/jama.288.18.2300

71. Michaëlsson K, Olofsson H, Jensevik K, Larsson S, Mallmin H, Berglund L, et al. Leisure physical activity and the risk of fracture in men. PLoS Med (2007) 4(6):e199. doi:10.1371/journal.pmed.0040199

72. Fielding RA, LeBrasseur NK, Cuoco A, Bean J, Mizer K, Fiatarone Singh MA. High-velocity resistance training increases skeletal muscle peak power in older women. JAm Geriatr Soc (2002) 50:655-62. doi:10.1046/j.1532-5415.2002.50159.x

73. Leenders M, Verdijk LB, van der Hoeven L, van Kranenburg J, Nilwik R, van Loon LJ. Elderly men and women benefit equally from prolonged resistance-type exercise training. JGerontol A Biol Sci Med Sci (2013) 68:769-79. doi:10.1093/gerona/gls241

74. Lieberman DE, Pearson OM, Polk JD, Demes B, Crompton AW. Optimization of bone growth and remodeling in response to loading in tapered mammalian limbs. J Exp Biol (2003) 206(Pt 18):3125-38. doi:10.1242/jeb.00514

75. Novotny SA, Mader TL, Greising AG, Lin AS, Guldberg RE, Warren GL, et al. Low intensity, high frequency vibration training to improve musculoskeletal function in a mouse model of Duchenne muscular dystrophy. PLoS One (2014) 9(8):e104339. doi:10.1371/journal.pone.0104339

76. Xie L, Rubin C, Judex S. Enhancement of the adolescent murine musculoskeletal system using low-level mechanical vibrations. J Appl Physiol (1985) (2008) 104:1056-62. doi:10.1152/japplphysiol.00764.2007

77. Krishnamoorthy D, Frechette DM, Adler BJ, Green DE, Chan ME, Rubin CT. Marrow adipogenesis and bone loss that parallels estrogen deficiency is slowed by low-intensity mechanical signals. Osteoporos Int (2016) 27:747-56. doi:10.1007/s00198-015-3289-5

78. Rubin CT, Capilla E, Luu YK, Busa B, Crawford H, Nolan DJ, et al. Adipogenesis is inhibited by brief, daily exposure to high-frequency, extremely low-magnitude mechanical signals. Proc Natl Acad Sci U S A (2007) 104:17879-84. doi:10.1073/pnas.0708467104

Conflict of Interest Statement: The authors declare that the research was conducted in the absence of any commercial or financial relationships that could be construed as a potential conflict of interest.

Copyright (c) 2016 Hamrick, McGee-Lawrence and Frechette. This is an open-access article distributed under the terms of the Creative Commons Attribution License (CC $B Y)$. The use, distribution or reproduction in other forums is permitted, provided the original author(s) or licensor are credited and that the original publication in this journal is cited, in accordance with accepted academic practice. No use, distribution or reproduction is permitted which does not comply with these terms. 